\title{
Media coverage of Christchurch mosque attacks in Western News Websites:
}

\author{
Thematic Analysis on BBC, CNN and DW \\ Dr. Eman Mohamed Soliman* \\ Dr. Hayat Badr Korany ${ }^{* *}$ \\ Dr. Sara Said El Maghraby****
}

\begin{abstract}
On March 15, 2019, Christchurch, New Zealand, witnessed mosque attacks on two consecutive mass shootings during Friday prayers. A single gunman who entered both mosques began at the Al Noor Mosque in the suburb of Riccarton at 1:40 pm and continued at Linwood Islamic Centre at 1:52 pm to kill 51 and injure 40.

This study seeks to analyse and compare the different western media coverage of these attacks in three media outlets: BBC, CNN, and DW, and to identify the media coverage's main themes. The researchers collected all news materials from all website sections related to the terror attacks, including news stories, features, and opinion pieces. The sample's time frame starts from March 15, 2019, to May 15, 2019, using quantitative content analysis and qualitative thematic analysis.

The study found that the highest number of published stories were in both DW and BBC. This study's main findings are four initial themes, the positive experience versus the negative experience related to the attack and the global, international level versus the attack's local level. The study concluded two final themes, the negative and the positive theme.
\end{abstract}

Keywords: Framing, Terror Attacks, Coverage, Thematic Analysis, Comparative Studies

\footnotetext{
${ }^{*} \mathrm{PhD}$. Lecturer, Faculty of Mass Communication, Cairo University

${ }^{* *} \mathrm{PhD}$. Lecturer, Faculty of Mass Communication, Cairo University

${ }^{* * *} \mathrm{PhD}$. Lecturer, Faculty of Mass Communication, Cairo University
}

The Scientific Journal of Public Relations and Advertising Research - Issue 21 - January / June 20211 


\section{Introduction:}

The terrorist incident in Christchurch, New Zealand mosque attacks in March 2019, with the shooting of worshipers before Friday prayers, had a significant impact on stirring up talk about the relationship of Islam and the West, peoples and countries.

Opinions differ in the relation between the media and Terror. From one side, the media has a significant role in increasing conflict and enhancing a lack of understanding between them. The media helps to transmit distorted stereotypes and hate speeches that are fuel for terrorist incidents. From the other side, media could play a role in building bridges of communication, exchanging cultures, and establishing a dialogue conveying sound and authentic images that affect public opinion. Over time, it can reduce Terror and hate.

Studies on Islam and the West in the media witnessed many developments and research perspectives dealing with media coverage during crises or Terror, whether in Arab or Western countries. These studies' results vary, but they mostly agree on the presence of distorted images of conflicting parties in the media coverage, which requires diplomatic and communication actions to enhance dialogue.

This study discusses these ideas and looks closely at an example of a terror. The researchers believe in a need to study the relationship between Islam and the West, the Islam and Muslims' image, and the causes and consequences of terror attacks.

Finally, this study represents an attempt to describe reality and provide future-suggested solutions and reach ways to build media treatments for different events that would enhance dialogue.

\section{Literature review}

Over the years, scholars have investigated media portrayals of minorities through the lenses of race, ethnicity, religion, and across varying geopolitical contexts. Muslims and Islam are at the crux of much censure and debate. (Ahmed \& Matthews, 2016). Western media has represented Muslims' negative image worldwide by contributing to various incidents like terrorism, suicide bombers, and hijacking. (Muhammad \& Taufiq, 2018). Also, the internet contributed to the spread of the negative image of Islam and Islamophobia, as they

The Scientific Journal of Public Relations and Advertising Research - Issue 21 - January / June 20212 
presented Islam as a religion that calls for Terror and Extremism. (Gaber, 2016)

After Osama bin Ladin's death, a study was conducted in two international new magazines: Economist and Time, to analyse the tendency to label Islam in association with terrorism. The results reveal that most of the coverage on issues related to Islam revolves around War and Terror. (Yusof et al. 2013)

Powel studied the media coverage of 11 terrorist events in the US between October 2010 and January 2010; it concluded that a pattern of media coverage of terrorism created a culture of fear of Islam and widened the gap between East and West present (Powel, 2011). Burik \&Ahmed analysed how the American website in the Arab language presents the war of terrorism; the main results show that the American website focuses on the theme of the renewal of religious discourse ( Burik \&Ahmed, 2017).

Alghamdi (2015) analysed how language was manipulated in the coverage of the 2011 Norway terrorists' attacks, revealing that the Western media held Muslims accountable without proof to support their claims. (Alghamdi, 2015)

According to studies, media frames the public discourse about Muslims and Islam in Europe and the United States. To determine the factors leading to the increased islamophobia, comparative secondary data analysis was conducted. The findings show that Islam and Muslims' negative perception is likely independent from religion but rather by political viewpoints. (Ogan et al., 2014).

A source's choice significantly determines the degree to which news articles are differentiated; a study seeks to analyse the terrorism coverage in three European countries (Austria, Germany and Switzerland) between 2015 to 2017. Results revealed that Non-Muslim sources and journalists are more likely to make undifferentiated statements about Muslims. They do not differentiate Muslim and Islam from Terror, affecting how citizens understand and perceive the news. (Matthes et al.2020).

Studies on Islam and Muslims' representation in the New Zealand media platforms show different perspectives; studies focused on 
framing Islam in the media. Others focused on the representation of the Christchurch massacre. In contrast, others focused on psychological factors.

Rahman and Emadi (2018) critically analysed a random sample of five news articles published between 2014 and 2016 regarding the written text and visual representation. Results show a tendency towards negative framing, falsification, and contradiction in the use of visuals. (Rahman and Emadi, 2018)

In the aftermath of the terrorist attacks, the study examines how national identity beliefs predict attitudes towards Muslims, using data from Time 7 of the New Zealand attitudes and values studies. It concluded that the New Zealanders' beliefs tend to endorse both ethnic and civic aspects, which is reflected negatively on their evaluation of minorities in general and Muslims in specific. (Yogeeswaran et al., 2019)

Another study compares attitudes towards Muslim with attitudes towards other religious groups. According to this study, there is more threat and negativity related to Muslims in comparison with other groups. (Greaves, R. et al. 2020).

After the Christchurch tragedy, Rahman conducted a study to analyse 12 news stories on the researcher's social media news feeds; the results show a substantial shift from the hostile othering rhetoric of international media to an inclusive national approach to the tone of the New Zealand press. This shift in the tone of the coverage enhances a better image of Islam and Muslims. (Rahman, 2020)

Ellis and Muller measure how proximity affects media coverage; by interviewing news executives and comparing the Australian and New Zealand coverage of the Christchurch attacks, they concluded that proximity was applied by local newsrooms, as New Zealand coverage was driven by Empathy toward the victims and their families, while the Australian nationality of the alleged gunman was fundamental in the news coverage. (Ellis \& Muller 2020) 


\section{Theoretical Framework:}

Framing Theory

Media plays a vital role in shaping and constructing how people view the world through framing. Framing Research seeks to explain how media organise events and how audiences interpret an issue (Ibrahim, 2010). Scholars study frames to detect trends in issue definitions, compare media coverage across multiple outlets, and explain differences across media types. (Chong \& Druckman, 2007)

Entman stated, "to frame is to select some aspects of a perceived reality and makes them more salient in a communication context" (Entman,1993). While Gitlin views frames as "the persistent patterns of cognition, interpretation, and presentation, of selection, emphasis, and exclusion, by which symbol-handlers routinely organise discourse" (Carte, 2013).

Goffman defines frames as the "schemata of interpretation," a framework that helps turn a meaningless series of events into something meaningful. (Borah, 2011). Stressing that framing is a way of constructing the surrounding environment indicates that journalists play a more active role in building media frames. (Strömback et al., 2008)

Frame building is one approach to framing research that focuses on how frames get established (Tweksbury \& Scheufele, 2009). Various factors influence the frame building process, including the social norms, values, ideology and political orientation of Journalists. (Rodriguez \& Dimitrova, 20011)

\section{Research Problem}

This study seeks to analyze the New Zealand attacks' media coverage in three news outlets (CNN, BBC \& DW) during the period from March 2019 to May 2019. This study uses thematic analysis as a tool of qualitative analysis to analyze how the different online news media outlets presented the New Zealand attacks. This study also uses the Framing as a theorical Framework to identify the different frames used in the three media outlets. 


\section{Research goals and objectives}

1- To understand the different frames of New Zealand attacks in three media outlets.

2- To identify the main themes of the media coverage of the New Zealand terror attacks.

3- To compare the coverage of $\mathrm{BBC}, \mathrm{CNN}$ and $\mathrm{DW}$ concerning the New Zealand attack.

\section{Research questions:}

RQ1: What are the frames that were used in the New Zealand attacks coverage in the three analyzed media outlets?

RQ2: What are the main themes of the media coverage of the New Zealand terror attacks?

RQ3: What are the differences and similarities between $B B C, C N N$ and $D W$ concerning the New Zealand attack?

\section{Methodology}

This study seeks to analyze the New Zealand attacks' media coverage in three news outlets (CNN, BBC \& DW). In the first phase, a pilot study was conducted on a sample of news websites to discover the case's availability in several international news websites. General remarks on the websites' content were taken. (Phase 1)

Data is collected from the news websites BBC, CNN, and DW about the New Zealand mosque attack. This study collected all news materials from all website sections related to the terror attack, including news stories, features, and opinion pieces. The time frame of the sample starts from March 15, 2019, to May 15, 2019. (Phase 2). In Phase 3, a 15category coding book was developed and applied to the stories of the sample. (Appendix 1)

Data Gathering and Data Corpus

Rizk et al. (2009) explained that conducting a thematic analysis consists of gathering all relevant news articles within a specific time frame and about the research study. The raw data constitute a data corpus. The data corpus is checked for relevance, and all invalid or irrelevant codes are derived and categorised. This paper focused on news articles

The Scientific Journal of Public Relations and Advertising Research - Issue 21 - January / June 20216 
available through three online sources of the selected news websites. The process included the selection of keywords (as search terms) using the following terms:

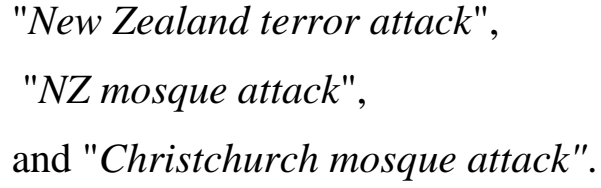

This study combines thematic Analysis to get in-depth information about how news outlets covered the attacks. Framing Analysis indicates the type of frames the news outlets implement. It applies all the steps suggested by (Braun \& Clarke 2006). As Braun and Clarke presented, the researchers analysed all the topics, ideas, and patterns of meanings from the texts. The steps used in this Analysis are: Familiarisation with the texts, coding them, generating, then reviewing and defining the themes.

The sample of the study

The study's population is the news websites that offer general content with a high number of visitors. These news websites were chosen because they reach many readers worldwide, offer different ideologies, and are known for their prestigious content. An analysis of three news websites is conducted on one American, one British, and one German. A two-month study period was performed on these news websites to cover the most relevant and valuable news content covering the mosque attack.

Choosing Sources and Gathering Meta Information:

Using the search terms, the resulting data corpus consisted of 70 articles in the three search engines. In the next step, these articles were analysed for inclusion into the data set. The sample could be described as the following:

1- $B B C$ that names itself the world's leading public service broadcaster, aims to educate and entertain audiences in the UK and worldwide. (https://www.bbc.com/aboutthebbc)

2- $C N N$ considers itself a world leader in online news and information and has almost 4 thousand journalists worldwide.

The Scientific Journal of Public Relations and Advertising Research - Issue 21 - January / June 20217 
Media coverage of Christchurch mosque attacks in Western News Websites

(https://edition.cnn.com/2014/01/17/cnninfo/about/index.html)

3- $D W$ defines itself as Germany's international broadcaster and one of the most influential global media outlets. (https://www.dw.com/en/about-dw/profile/s30688\#: :text=Our\%20Mission,to\%20form\%20their\%20own\%20 opinions )

\section{Findings:}

The data analysis approach for this study is thematic Analysis. In the first step, the authors familiarize themselves with the data; then assemble codes into potential themes; In the third step, they review, name, and define the themes. Then the themes are analysed in the scope of research questions and related literature. The themes and patterns within the data are identified using the inductive or "bottom-up" approach.

In this part of the study, we aim to present the data gathered from news websites. According to our methodology, we are combining quantitative and qualitative. First, the quantitative content analysis presents preliminary indicators about the distribution of the articles according to news outlets, sample time frame, news sections, type of articles, and the frames used. Afterwards, a step-by-step thematic analysis is carried out.

Part One: Quantitative Content Analysis

In the first part of the findings, this study uses quantitative content analysis implementing framing analysis to quantify, analyse and indicate the frames used to present the data collected.

Table 1.: Sample of News websites. (Source: Authors)

\begin{tabular}{lll}
\hline & Number of stories & Percentage \\
\hline CNN & 20 & $28.6 \%$ \\
\hline BBC & 25 & $35.7 \%$ \\
\hline DW & 25 & $35.7 \%$ \\
\hline
\end{tabular}

The Scientific Journal of Public Relations and Advertising Research - Issue 21 - January / June 20218 
As seen in Table 1., the tested sample (N:70) shows the following characteristics: the highest number of published stories were in both DW and BBC with a percentage of $35.7 \%$. CNN came in second place in the number of stories published about the New Zealand attacks, with $28.6 \%$ of the stories.

Fig.1.: Number of stories on the time sample (Source: Authors)

number of published articles during the initial three months of the terrorist attack

(March-April- May)

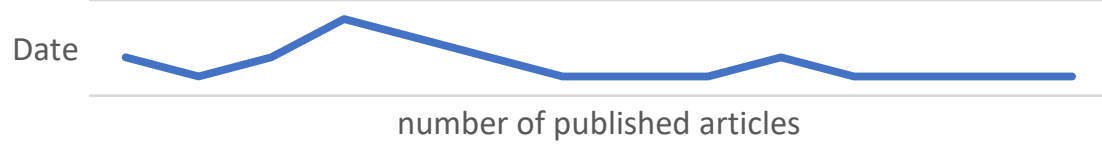

Fig.1. depicts the published articles' distribution during the three-month post-Christchurch mosque shooting in the analyzed media (BBC, CNN DW). Most articles were published on the attack day, which is March 15, 2019. Then the following two days, but the shooting's media coverage dropped significantly over time.

Table 2: Website News Sections (Source: Authors)

\begin{tabular}{lll}
\hline & Number of stories & Percentage \\
\hline International news & 36 & $51.4 \%$ \\
\hline News & 21 & $30 \%$ \\
\hline Business & 5 & $7.1 \%$ \\
\hline Opinion & 2 & $2.9 \%$ \\
\hline Politics & 2 & $2.9 \%$ \\
\hline Society & 2 & $2.9 \%$ \\
\hline US news & 1 & $1.4 \%$ \\
\hline Asia & 1 & $1.4 \%$ \\
\hline
\end{tabular}

The Scientific Journal of Public Relations and Advertising Research - Issue 21 - January / June 20219 
Media coverage of Christchurch mosque attacks in Western News Websites

As seen in Table 2, the results show that more than half of the stories were published in the international news section, 51.4\% as the shooting took place in New Zealand. The media outlet analyzed were American CNN, British BBC and German DW. In second place came the news section with a percentage of $(30 \%)$. Then in third place came the Business section. In the fourth place, two articles published in the Opinion section, Politics and Society, and finally, one article published in the US News and Asia section tackled the shooting.

Table 3: Types of stories published about the New Zealand attack (Source: Authors)

\begin{tabular}{lll}
\hline & Number of stories & Percentage \\
\hline News report & 55 & 78.6 \\
\hline Feature & 6 & 8.5 \\
\hline Editorial & 5 & 7.2 \\
\hline Opinion & 3 & 4.3 \\
\hline Photos only & 1 & 1.4 \\
\hline Results showed that & most of the piecespublished & \\
\hline
\end{tabular}

Results showed that most of the pieces published were news reports, 78.6\%. They are essential in presenting all relevant facts and representing a complete story, coming in second place the news features articles $(8.5 \%)$. These types of articles focus on human interest aspects. Followed by Editorial, then Opinion and finally photos only.

RQ1: What are the frames that were used in the New Zealand attack coverage in the three analyzed media outlets?

Table 4: The Frames in the stories: (Source: Author)

\begin{tabular}{lll}
\hline Frame & Number of stories & Percentage \\
\hline Terror & 32 & 45.7 \\
\hline Empathy & 18 & 25.7 \\
\hline Human interest & 14 & 20 \\
\hline Blame & 6 & 8.6 \\
\hline
\end{tabular}

The Scientific Journal of Public Relations and Advertising Research - Issue 21 - January / June 202110 
As seen in Table 4, 32 stories include positive frames (18 frames for Empathy, 14 frames for Human interest). The negative frames are in 38 stories (32 frames of Terror and six frames for Blame).

RQ2: What are the main themes of the media coverage of the New Zealand terror attacks?

Part Two: Qualitative Thematic Analysis:

In the second part of the findings, we present steps of the thematic analysis, as follows:

\section{Step 1: Familiarizing with the data and generating initial codes}

The thematic Analysis's first step is to familiarize with the gathered data through a repeated reading to find potential meanings and patterns. The second step is to produce initial codes to generate meaningful, abstract categories that would later allow the research group to develop themes and better understand the phenomenon.

\section{Table 5: Initial codes and examples (Source: Authors)}

\begin{tabular}{|c|c|c|}
\hline $\begin{array}{l}\text { Initial } \\
\text { code }\end{array}$ & Definition & Example \\
\hline $\begin{array}{l}\text { Afraid of } \\
\text { Terror } \\
\text { attack }\end{array}$ & $\begin{array}{l}\text { The author links the } \\
\text { attack to the general idea } \\
\text { of terror and terrorism } \\
\text { and national security. }\end{array}$ & 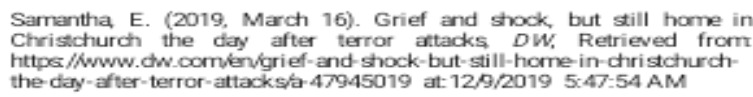 \\
\hline $\begin{array}{l}\text { Fear from } \\
\text { violence } \\
\text { and } \\
\text { extremism }\end{array}$ & $\begin{array}{l}\text { The author expresses his } \\
\text { fear of the attackers and } \\
\text { their violenoe. }\end{array}$ & 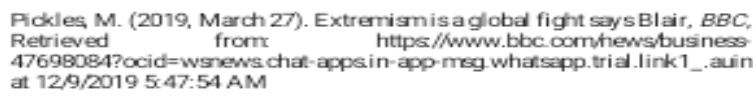 \\
\hline $\begin{array}{l}\text { Discussing } \\
\text { authorities }\end{array}$ & $\begin{array}{l}\text { The author discusses } \\
\text { authorities security } \\
\text { measures rescue and } \\
\text { medical support. }\end{array}$ & 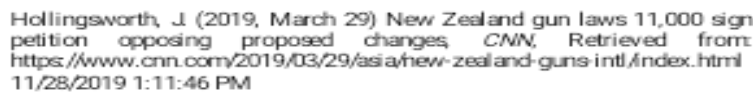 \\
\hline $\begin{array}{l}\text { Showing } \\
\text { support for } \\
\text { victims }\end{array}$ & $\begin{array}{l}\text { The author explains a } \\
\text { humen aspect in the story } \\
\text { to support the attack } \\
\text { victims and show } \\
\text { empathy. }\end{array}$ & 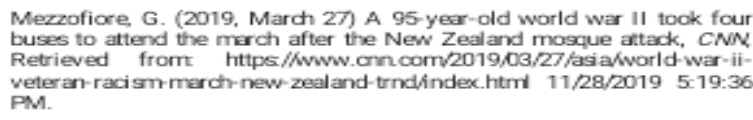 \\
\hline $\begin{array}{l}\text { Describing } \\
\text { the attack }\end{array}$ & $\begin{array}{l}\text { The author describes } \\
\text { what happened in the } \\
\text { attack the actions that } \\
\text { took place during the } \\
\text { attack }\end{array}$ & $\begin{array}{l}\text { Christchurch shooting, (2019, March 15) } B B C \text {, Retrieved from } \\
\text { https//www.bbcoomwews/world-asia-47578/98 12/2/2019 8:14:47 AM }\end{array}$ \\
\hline
\end{tabular}

The Scientific Journal of Public Relations and Advertising Research - Issue 21 - January / June 202111 


\section{Step 2: Identifying initial themes:}

After generating initial codes, the next step is to identify specific themes and patterns within the data. We did this by analyzing the codes and trying to allocate them into separate comprehensive categories. This study has resulted in four initial themes, as explained in the coming lines: The positive experience versus the negative experience related to the attack and the global, international level versus the attack's local level.

Initial Theme Number One: Positive experiences related to the attack:

This theme tackles the positive measures and reactions that followed the New Zealand attacks. Some of these positive experiences are the unity between Muslims and non-Muslims and the solidarity against Terror. It also includes some positive measures that the government took to stop racism. An example of this is "New Zealand bans semiautomatic, automatic weapons" (2019, March 21).

Initial Theme Number Two: Negative experiences related to the attack:

This theme includes all the negative aspects that are related to the mosque attack. These aspects include the number of deaths, the brutality of the attack, and the racism against Muslims. Some examples for these stories are: "Death toll rises in New Zealand terror attack" (2019, March 16) and a story by Cullinane, S. (2019, March 18).

Initial Theme Number Three: Local experiences related to the attack:

This theme explains local events pre-attack and the provincial governments and locals' reactions to the attack. It also discusses incidents that happened in the mosque and measures taken. For instance, the number of the death as in this story: "Suspected Christchurch gunman to face 50 murder charges", (2019, April 4).

Initial Theme Number Four: Global or international experiences related to the attack:

This theme discusses the international or the global perspective of the attack. It explains the international reactions towards the attack, the condemnation of the attacks and attackers, and the support against Terror. This theme also includes the measures taken by some other countries as a reaction to the New Zealand attacks. For Example,

The Scientific Journal of Public Relations and Advertising Research - Issue 21 - January / June 202112 
Zurcher A. (2019, March 21) discusses the US gun laws from the New Zealand attack perspective.

This theme also includes Turkey's condemnation and its president Erdogan spreading the news about the attack by reposting the video. Several stories discuss the role of Erdogan's hate speeches and reactions to terror attacks as being a cause for more violence. Examples are stories like "Turkey's Erdogan shows Christchurch mosque reshooting video despite protest from New Zealand" "(2019, March 21).

\section{Step 3: Reviewing and defining final themes:}

Researchers agreed that there is an important step, which is the revision of initial themes. We have reduced the themes from four to two themes. The local and the global experiences about the attack were added to the final two themes. If the local or international experience is positive, then it will be added to the positive final theme, and if negative, it will be added to the negative theme. The last themes are positive experiences related to the attack versus negative experiences related to the attack.

Fig. 2 Visual explanation of the final themes. (Source: authors)

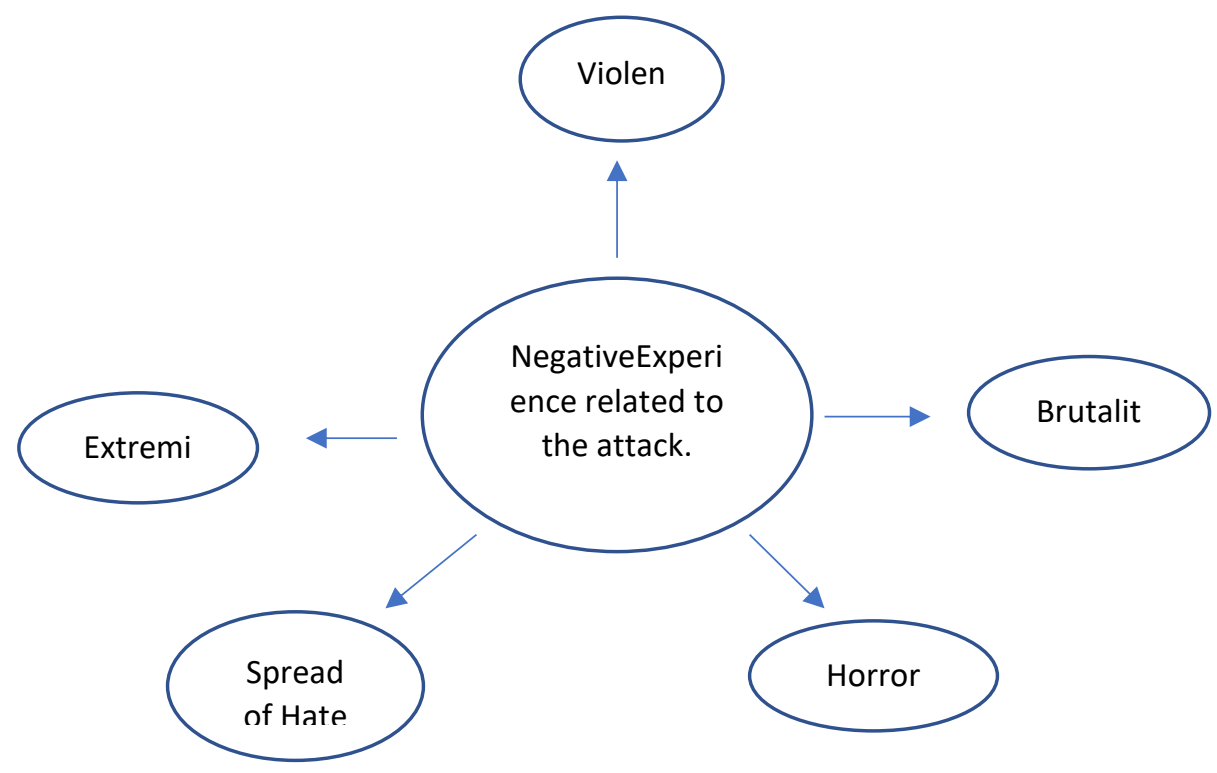

The Scientific Journal of Public Relations and Advertising Research - Issue 21 - January / June 202113 
Final Theme: Number One: Positive experience related to the attack:

Positive experiences related to the attack explain learned lessons from the attack and supportive emotions related to the attack. This final theme also includes better connection and interaction between Muslims and non-Muslims in society, whether locally or globally. Examples of these stories include a synagogue in Pittsburgh raising "45000 dollars for New Zealand mosque attacks victims". Another story that provides a positive theme is how, in the aftermath of the Zealand terror, world leaders have expressed the "senseless violence" and condemned the attack. Another story tackles how thousands of locals showed up to Christchurch "vigil to shun racism". Another opinion piece is discussing how non-Muslims should show support to Muslim victims.

Besides, the positive experience related to the attack includes the ban on gun violence, right-wing and extremist ideas and groups in societies locally and globally. An example is stories discussing how Facebook is considering banning white nationalism and separatism and how New Zealand regulates laws to ban semi-automatic and automatic weapons.

Furthermore, the positive experiences also mean that the analyzed websites cover success stories related to Muslims and a better understanding of Islam in an Islamic country. For Example, "within hours of the Christchurch mosque attacks, people of various faiths rallied around Muslim"(2019, March 15) "New Zealand mourns mosque attack victims in the national day of reflection." (2019, March 22) and "A 95-year-old World War II took four buses to attend the march after the New Zealand mosque attack" (2019, March 27) .

Finally, this theme consists of measures taken to protect and secure mosques in New Zealand and outside. Austria- for instance- may disband far-right group over the link to New Zealand attack suspect. While New Zealand gun laws 11,000 sign petition opposing proposed changes. and "royals lead global tributes after Christchurch terror attack" (2019, March 15).

Final Theme Number Two: Negative Experiences related to the attack:

Negative experiences related to the attack explain the violence, brutality and Extremism associated with the attacks. The number of deaths, the scene's cruelty, and the horror and panic associated with the attacks are

The Scientific Journal of Public Relations and Advertising Research - Issue 21 - January / June 202114 
part of this theme. Whether locally or internationally, the negativity related to this massacre are included in this theme.

Examples of local experiences are how the twin terrorist attacks killed dozens at Christchurch mosques, the number of deaths in the New Zealand shooting that reached 49 , how the shooting eyewitness heard a gun. It also describes how the first bodies returned to their families. Some other examples include the New Zealand prime minister's speeches describing the brutality of the attack and explaining how the mass shooting suspect has obtained his guns legally.

Examples for international experiences are: "Birmingham mosques on heightened alert after the attack" (2019, March 22) "Austrian far-right activist probed over links to Christchurch attack" (2019, March 27), "Turkey's Erdogan shows Christchurch mosque shooting video again despite protest from New Zealand" (2019, March 21).

RQ3: What are the differences and similarities between $B B C, C N N$ and $D W$ concerning the New Zealand attack?

In this part of the findings, we discuss the different aspects of the three media outlets' coverage. We discuss how the BBC, CNN and DW vary in their content to the New Zealand attack and how they focus on different story angles.

$\mathrm{BBC}$ focuses mainly on the Australian reactions towards the coverage. For Example, it covers Fraser Anning, the Australian minister-president who was convicted for appealing Christchurch remarks and other stories. It also focuses on providing the reader with the Christchurch shooting in details and minute after minute. The BBC is also the only medium between the three-sample media that discusses the UK's reactions to its prime minister Blair towards the attack. (2019, March 27 . Another aspect that the BBC covered in depth is the reaction of other mosques after the attack, such as the Birmingham mosque. It covers a story on how Birmingham mosques have heightened the security and precautions after the New Zealand attack. (March 22, 2019). In Birmingham and Scotland, the BBC focuses on the measures that mosques in Scotland took after New Zealand. (Example: Mosques could be given Scottish government cash to improve security (2019, March 18).

The Scientific Journal of Public Relations and Advertising Research - Issue 21 - January / June 202115 
Another aspect that the BBC covered is the reactions of Turkey and its prime minister to the massacre. In a story entitled: Why Erdogan's big ambition could come tumbling down, (March 28, 2019) also discusses how Facebook is reacting towards the New Zealand attack by banning white nationalism and separatism as a reaction to violence and terror attacks. (2019, March 28)

When taking a more in-depth look, we find that $\mathrm{CNN}$ is the medium that discusses the most the events that reunited the people in New Zealand together such as the story:" within hours of the Christchurch mosque attacks, people of various faiths rallied around Muslim". As well as a story of a "95-year-old world war II took four buses to attend the march after the New Zealand mosque attack" (2019, March 27). It also covers how non-Muslims are willing to offer support to the attacks held on the mosque.

It is most of all mediums to discuss the role of social media in promoting violence and aggression. Stories discuss the role of Facebook in promoting the mosque attack video as in the story: "New Zealand wants an answer from Mark Zuckerberg over mosque attack video" (2019, March 20) and another story on "how hashing could stop violent videos from spreading" (2019, March 15). Another story on how "Facebook, YouTube and Twitter struggle to deal with New Zealand shooting video" (2019, March 15).

$\mathrm{CNN}$ focuses on the procedures and the local events during the attack. Some of these stories are, for instance, "First bodies returned to families as New Zealand PM calls for unity after Christchurch attack" (2019, March 19) and "New Zealand shooting suspect appears in court". It also discusses how "New Zealand gun laws 11,000 sign petition opposing proposed changes (2019, March 29).

When analysing the content presented in DW about the New Zealand attack, we find that the focus is on international reactions. For Example, we found several stories, New Zealand terror attacks: World Leaders voice dismay at the senseless violence. DW also focuses on Turkey's reactions, like in the story "Turkey's Erdogan shows Christchurch mosque reshooting video despite protest from New Zealand" (2019, April 7). 
In DW, there was also a focus on the statements given by Prime Minister Jacinda Ardern. Like New Zealand, PM vows mosque attackers will remain nameless, and New Zealand terror attacks. "Jacinda Arden's government to announce gun law reforms within ten days." (2019, April 7).

There is also special attention given to the massive attack and an emotional description of the attack. Examples of these types of stories are "New Zealand mosque attack: the first funeral held and story" (2019, March 24) and Early, S. (16. March 2019).

Furthermore, DW is most of the sample of this study to link this event to the right-wing and Extremism worldwide discussing Terror towards Muslims. An example is a story: "Austrian far-right identarian Movement investigated over New Zealand attacker link" (2019, March 27) and "New Zealand bans semi-automatic, automatic weapons" (2019, March 21).

One of the highlights of the coverage is the human story that DW has published about the New Zealand hero who saved lives during the attack. Strack, C. (2019, March 22)

It is also the only medium that called for the necessity of showing support from non- to Muslims. This story is "Opinion: After New Zealand, non-Muslims should show support." (2019, April 4).

\section{Conclusion:}

This study analyses how Western news channels websites covered New Zealand's mosque attacks; BBC, CNN and DW. The study also seeks to compare the coverage of the three news channels websites' coverage, using quantitative content and thematic Analysis between March 15, 2019, and May 15, 2019. The main results show that most news stories were published in DW and BBC in terms of numbers. While with a slight difference, CNN. came in second place, although it is one of the leading global news networks.

Compared to the other two news websites, the low coverage of CNN does not mean a lack of interest in this terror attack. According to US studies, the US media covered the attacks in non-Muslim-majority societies. They framed them as acts of terrorism (El-Masry \& AlNawawy, 2020), while these terrorist attacks did not negatively affect

The Scientific Journal of Public Relations and Advertising Research - Issue 21 - January / June 202117 
Americans' thermometer feelings toward Muslims. (Boydstun et al., 2018).

The media coverage focused on describing and explaining the incident, presenting all relevant facts. Therefore, news reports were the primary form used to cover the shooting, especially as the examined period began from March 15 - the day of the incident- till May 2019.

In terms of frames, studies show that significant terrorism attacks tend to receive intense media coverage, which is often framed differently across different online news channels; the results show that the main frame used was Terror. We can explain that the Terror frame is the most suitable to be used in a massacre as big as the New Zealand mosque attacks. This result comes in agreement with Al Saeed 2016 study, that the conflict frame that focuses on Terror is the main frame of the media coverage of terror attacks.

In terms of the humanitarian perspective, Empathy was the second frame online news channels used in their media coverage. After explaining the aspects of horror and blood, the empathy frame focuses on the suffering of the injured and the Muslim community in New Zealand and the support of non-Muslims.

As for the qualitative analysis, the results revealed two main themes: positive experience related to the attack VS negative experience related to the attacks. The first central theme focused on the positive experience related to the attack regarding social support and community connectedness between Muslims and non-Muslims.

Furthermore, the terror attack raised awareness about the necessity of amending the Human Rights Act 1993, which now became an election issue, to make it illegal to threaten people because of their religious Identity. (Hate crimes against Muslims spiked after the Christchurch mosque attacks - NZ Herald)

As for the negative experience related to the attacks, it focused on casualties and the brutality of the attacks in addition to white supremacist, according to special report about how the British media report on terrorism it indicated that in 2019, online news media shows a higher level of consistency in describing far right or white supremacist inspired attacks as terrorism

The Scientific Journal of Public Relations and Advertising Research - Issue 21 - January / June 202118 
Researchers discussed how the $\mathrm{BBC}, \mathrm{CNN}$, and $\mathrm{DW}$ vary in their content to the New Zealand attack and how they focus on different story angles.

We see a different focus on some of the elements within the coverage. In general, all three news websites covered how the locals (government, ministers, etc.) in their countries reacted to the attacks.

Because of the historical ties between the UK and Australia, we found that $\mathrm{BBC}$ focuses mainly on the Australian reactions towards the coverage. It also focuses on providing the reader with the Christchurch shooting in details and minute after minute. Following the Christchurch attacks, the British online media adopted the context-oriented coverage, which focused on providing background for the attack. (Papacharissi \& Oliveira, 2008)

$\mathrm{CNN}$ is the most among all mediums to discuss social media's role in promoting violence and aggression, as digital technology was an integral and integrated component of the attack. CNN focused on stories about the role of Facebook in promoting the mosque attack video. The role of the live streaming of the Christchurch mosque attacks resulted in accelerating the experience of real-time witnessing death on multiple levels. While a relatively small number of people watched the massacre take place. (Tikka et al., 2020)

This could be explained that CNN represents the US media and is generally focusing heavily on social media's role in promoting Terror and violence. The US is also one of the most developed countries related to technology, the internet and social media platforms. The readers of CNN might be interested in getting information about how social media could promote, distribute, and sharpen Extremism and violence.

DW, which represents the German point of view, gives special attention to Turkey's reactions and its Prime Minister Erdogan in distributing the violent video scenery. This could be explained considering the relation between Germany and Turkey. It is known that the political relations between Turkey's Erdogan and German's Merkel are witnessing several hidden tensions. As Turkey is trying to get into the EU, being an Islamic country, and having the biggest minority group in Germany, some conflicts are raised in their mutual relationship over the 
years. Furthermore, DW is the most news website, which focused on linking the terror attack to the right-wing and Extremism worldwide discussing Terror towards Muslims.

As Germany has suffered from Extremism and right-wing violence, we understand that DW's focus is on the attack's extremist aspects. Over the past decades, Germany has witnessed a few terror attacks, assaults and discrimination towards its minorities, especially Muslims. Neo nazists and extremists call for ending Germany's Islamic occupation, especially after the enormous number of Syrian refugees accepted by Germany.

\section{Limitations:}

The findings of this study must be seen considering some limitations:

This study combines the quantitative represented in content analysis and qualitative represented in thematic Analysis. The content analysis helped quantify and analyze how the three western online news websites presented the terror attack. On the other hand, thematic Analysis provided the researcher with an in-depth view of the results.

One of the main problems of convenience is sampling bias. It is often beyond the researcher's control. But we are aware that this sample is not representative of the Western media and that this paper's results could not be generalized.

We are also aware that the three news websites do not represent the media's view in their country in general and could not be referred to as German, British or US media.

This paper's limitations are also in the case study of the terror attack of New Zealand and the lack of comparison between other terror attacks that happened in other parts of the world. We see that this one event could reflect or indicate the coverage of terror attacks in general from Western media.

\section{Future Directions:}

We suggest future research on different news websites, newspapers, magazines and TV channels from other parts of the world in different cultural and religious contexts.

The Scientific Journal of Public Relations and Advertising Research - Issue 21 - January / June 202120 
Comparative studies regarding culture analysis to study how different media outlets cover the New Zealand attack and how different professional newsrooms cover different terror attacks.

Furthermore, analytical studies could be applied to examine different terror attacks that targeted Muslim versus Non-Muslim groups. We claim that the coverage of the western media, in general, could be more emotional in its discourse if the terror attack is related to its majority. Here, it is helpful to understand the variables that affect the media discourse towards various terror attacks.

It is helpful to dig deeper into analyzing the numerous variables that affect the media coverage of terror attacks in general and terror attacks against Muslims in specific. These variables include the religion of the targeted group of the terror attack, the attacker's religion, the media outlets' type, and its societal and cultural context.

Another suggestion could be choosing a decade or two periods and mark all terror attacks that the world has witnessed. A research group could analyze the media discourse and question the representation of the media throughout the year. Here, the study's aim discourse's production would be to what extent the coverage changed or stayed the same. 
Media coverage of Christchurch mosque attacks in Western News Websites

\section{References}

1. "95-year-old world war II took four buses to attend the march after the New Zealand mosque attack" (2019, March 27) Retrieved from https:/www.cnn.com/2019/03/27/asia/world-war-ii-veteran-racism-march-newzealand-trnd/index.html

2. Ahmed, S., \& Matthews, J. (2016). Media representation of Muslims and Islam from 2000 to 2015: A meta-analysis. International Communication Gazette, 79(3), 219-244. DOI: $10.1177 / 1748048516656305$

3. Alghamdi, E. (2015). The Representation of Islam in Western Media: The Coverage of Norway Terrorist Attacks. International Journal of Applied Linguistics and English Literature, 4(3). DOI: 10.7575/abactinally. v.4n.3p.

4. Al Saeed, S. (2016). New Coverage frames of International and Arab terrorism events in international Arab newspapers, Egyptian Journal of Mass Communication Research, (57), 33-87 doi 10.21608)EJSC.2016.89061

5. "Austrian far-right identarian Movement investigated over New Zealand attacker link" (2019, March 27), DW, Retrieved from https://www.dw.com/en/austrian-farright-identitarian-movement-investigated-over-new-zealand-attacker-link/a48070951 at 11/26/2019 9:12:34 AM

6. Borah, P. (2011). Conceptual Issues in Framing Theory: A Systematic Examination of a Decade's Literature. Journal of Communication 61 .246-263

7. Boydstun, A. E., Feezell, J. T., \& Glazier, R. A. (2018). In the wake of a terrorist attack, do Americans' attitudes toward Muslim's decline? Research\& Politics. https://doi.org/10.1177/2053168018806391

8. Braun, V. and Clarke, V. (2006). Using Thematic Analysis in Psychology. Qualitative Research in Psychology, 3, 77-101.

9. Burik, A. M. \& Ahmed, E. A. (2017). The War on Terrorism as Presented in the Video Journalism in Egyptian and American Website in Arab Language. Egyptian Journal of Mass Communication Research, (60),191-279. http//doi. /ejsc.2017.87906/10.21608 (in Arabic)

10. Carter, M. J. (2013). The Hermeneutics of Frames and Framing: An Examination of the Media's Construction of Reality. SAGE Open. https://doi.org/10.1177/2158244013487915

11. Center for Media Monitoring. (2020) How the British Media reports on Terrorism, Retrieved from https://cfmm.org.uk/wp-content/uploads/2020/08/CfMM-HowBritish-Media-Reports-Terrorism-ONLINE.pdf

12. Chong, D. and Druckman, J. N. (2007). Framing Theory. Annual Review of Political Science. 10. 103-126.

13. "Death toll rises in New Zealand terror attack", (2019, March 16) DW, retrieved from https://www.dw.com/en/death-toll-rises-in-new-zealand-terror-attack/a47950304 at 11/28/2019 9:13:50 AM

14. Early, S. (16. March 2019) Grief and shock, but still home in Christchurch the day after, $D W$, Retrieved from https://www.dw.com/en/grief-and-shock-but-stillhome-in-christchurch-the-day-after-terror-attacks/a-47945019 at 11/28/2019 8:57:55 AM.

The Scientific Journal of Public Relations and Advertising Research - Issue 21 - January / June 202122 
15. Ellis, G. \& Muller, D. (2020). The proximity filter: the effect of distance on media coverage of the Christchurch mosque attacks, Kōtuitui: New Zealand Journal of Social Sciences Online, 15:2, 332-348, DOI: 10.1080/1177083X.2019.1705358.

16. Elmasry, M. H., \& el-Nawawy, M. (2020). The value of Muslim and non-Muslim life: A comparative content analysis of elite American newspaper coverage of terrorism victims. Journalism. https://doi.org/10.1177/1464884920922388

17. Entman, R. M. (1993). Framing: Toward Clarification of a Fractured Paradigm. Journal of Communication. 43(4). 51-58

18. "Facebook, YouTube and Twitter struggle to deal with New Zealand shooting video" (2019, March 15). Retrieved from: https://www.cnn.com/2019/03/15/tech/new-zealand-shooting-video-facebookyoutube/index.html.

19. "First bodies returned to families as New Zealand PM calls for unity after Christchurch attack" (2019, March 19) Retrieved from https://www.cnn.com/2019/03/19/asia/new-zealand-mosque-shootingintl/index.html

20. Gaber, E. A. A. (2016). The Role of the Social Media Network in Correcting the Islam Image on the Internet. Egyptian Journal of Mass Communication, (55), 241 316. DOI: 10.21608/ejsc.2016.90465 (in Arabic)

21. Greaves, L. M. Rasheed, A., D'Souza, S., Shackleton, N., Oldfield, L. D. Sibley, C. G. Milne, B. \& Bulbulia, J. (2020). Comparative Study of Attitudes to Religious Groups in New Zealand Reveals Muslim-Specific Prejudice, Kōtuitui: New Zealand Journal of Social Sciences Online. 15:2, 260-279, DOI: 10.1080/1177083X.2020.1733032

22. "How hashing could stop violent videos from spreading" (2019, March 15) Retrieved from https://www.cnn.com/2019/03/15/tech/new-zealand-video-viralsocial-media/index.html

23. Ibrahim, D. (2010). The Framing of Islam on Network News Following the September 11 attack. The International Communication Gazette, 72(1).111-125

24. Ittefaq, M. \& Ahmad, T. (2018). Representation of Islam And Muslims on Social Media: A Discourse Analysis of Facebook. 10.17349/jmc118103.

25. "Jacinda Arden's government to announce gun law reforms within ten days." (2019, April 7) https://www.dw.com/en/new-zealand-terror-attacks-pm-jacindaarderns-government-to-announce-gun-law-reforms-within-10-days/a-47957408

26. Matthes, J., Kaskeleviciute, R., Schmuck, D., Von Sikorski, C., Klobasa, C., Knupfer, H. \& Saumer, M. (2020). Who Differentiates between Muslims and Islamist Terrorists in Terrorism News Coverage? An Actor-based Approach, Journalism Studies, DOI: 10.1080/1461670X.2020.1812422.

27. "New Zealand bans semi-automatic, automatic weapons", (2019, March 21) DW, Retrieved from https://www.dw.com/en/new-zealand-bans-semi-automaticautomatic-weapons/a-48003812 at 11/28/2019 8:39:43 AM.

28. "New Zealand gun laws 11,000 sign petition opposing proposed changes (2019, March 29) Retrieved from https://www.cnn.com/2019/03/29/asia/new-zealandguns-intl/index.html."

The Scientific Journal of Public Relations and Advertising Research - Issue 21 - January / June 202123 
Media coverage of Christchurch mosque attacks in Western News Websites

29. "New Zealand wants an answer from Mark Zuckerberg over mosque attack video" (2019, March 19) Retrieved from_https://www.cnn.com/2019/03/19/tech/newzealand-attack-video-zuckerberg/index.html

30. Ogan, C., Willnat, L. \& Pennington, R. \& Bashir, M. (2013). The rise of antiMuslim prejudice: Media and Islamophobia in Europe and the United States. International Communication Gazette. 76. 27-46. 10.1177/1748048513504048.

31. "Opinion: After New Zealand, non-Muslims should show support." (2019, April 4) retrieved from https://www.dw.com/en/opinion-after-new-zealand-nonmuslims-should-show-support/a-48014414 at 11/26/2019 9:19:11 AM.

32. Papacharissi, Z., \& de Fatima Oliveira, M. (2008). News Frames Terrorism: A Comparative Analysis of Frames Employed in Terrorism Coverage in US and UK Newspapers. The International Journal of Press/Politics, 13(1), 5274. https://doi.org/10.1177/1940161207312676

33. Powell, K. A. (2011) Framing Islam: An Analysis of US Media Coverage of Terrorism Since 9/11, Communication Studies, 62:1, 90-112, DOI 10.1080/10510974.2011.533599.

34. Rahman, K., \& Emadi, A. (2018). Representations of Islam and Muslims in New Zealand media. Pacific Journalism Review: Te Koakoa, 24(2), 166-188. DOI: 10.24135/pjr. v24i2.419

35. Rahman, K. (2020). News media and the Muslim Identity after the Christchurch Mosque Massacres, Kōtuitui: New Zealand Journal of Social Sciences Online, 15:2, 360-384, DOI: 10.1080/1177083X.2020.1747503.

36. Rizk, R.; Marx, D.; Schrepfer, M.; Zimmerman, J.; and Guenther, O., (2009) "Media Coverage of Online Social Network Privacy Issues in Germany: A Thematic Analysis." AMCIS 2009 Proceedings. 342. Retrieved from: https://aisel.aisnet.org/cgi/viewcontent.cgi?article=1335\&context=amcis2009

37. Rodriguez, L. \& Dimitrova, D. (2011) The Levels of Visual Framing. Journal of Visual Literacy. 30(1). 48-65.

38. Strack, C. (2019, March 22). New Zealand terror attacks: The Hero of Christchurch talks, $D W$, Retrieved from https://www.dw.com/en/new-zealandterror-attacks-the-hero-of-christchurch-talks/a-47955945 at 11/26/2019 9:19:11 AM

39. "Suspected Christchurch gunman to face 50 murder charges, (2019, April 4)" DW, Retrieved from https://www.dw.com/en/suspected-christchurch-gunman-to-face50-murder-charges/a-48193233at 11/26/2019 9:00:17 AM.

40. Strömback, J., Shehata, A. \& Dimitrova, D. (2008) Framing the Mohamed Cartoons Issue: A Cross-Cultural Comparison of Swedish and US Press. Global Media \& Communication. 4(2). 117-138

41. "Turkey's Erdogan shows Christchurch mosque reshooting video despite protest from New Zealand" (2019, March 21), DW, Retrieved from https://www.dw.com/en/turkeys-erdogan-shows-christchurch-mosque-shootingvideo-again-despite-protest-from-new-zealand/a-48013741 at 11/26/2019 10:20:31 AM.

42. Oliver, M. B., Raney, A. A., \& Bryant, J. (2019). Media Effects: Advances in Theory and Research. Taylor \& Francis. https://books.google.es/books?id=c0yfDwAAQBAJ

The Scientific Journal of Public Relations and Advertising Research - Issue 21 - January / June 202124 
43. Yogeeswaran, K., Wang, M., Devos, T., Sibley, C., Afzali, U., Andrews, N. \& Chivers, L. (2019). Exploring New Zealand National Identity and Its Importance for Attitudes toward Muslims and Support for Diversity. New Zealand: Journal of Psychology. 48. 29-35.

44. Yusof, S., Hyati, H., Fauziah, H., Md Salleh, Osman, M. (2013). The Framing of International Media on Islam and Terrorism. European Scientific Journal. 9(8). 104-121

45. Tikka, M. T., Sumiala, J., Harju, A., \& Valaskivi, K. (2020). Weaponization of Liveness: Streaming death as a hybrid Media event of Terrorist violence. AoIR Selected Papers of Internet Research, 2020. https://doi.org/10.5210/spir.v2020i0.11349

46.Zurcher A. (2019, March 21) "US gun laws", BBC, retrieved from https://www.bbc.com/news/world-us-canada-41489552?ocid=wsnews.chatapps.in-app-msg.whatsapp.trial.link1_.auin at 12/9/2019 5:28:41 AM

\section{Appendix 1}

\section{Coding Sheet}

1- Medium: $1=\mathrm{BBC} ; 2=\mathrm{CNN} ; 3=\mathrm{DW}$

2- Author: given in full

3- Date: given in full

4- Section: $1=$ international news; $2=$ politics, $3=$ society

5- Format: 1= news report; $2=$ editorial; $3=$ column; $4=$ feature; $5=$ other

6- Headline:

7- Sub-headline:

8- Main theme: Main statement:

9. Sub theme:

10- Frame: 1=Human Interest 2= Empathy 3= Blame 4= Terror 5=other

11- Symbols: $1=$ Hijab 2= minaret 3=Beard 4= Prayers 5= Candles $6=$ other

12- Terminology used to describe Muslims: $1=$ minority 2=Muslim 3=Islamists 4=victims 5=people 6=new Zealand's $7=$ other

13- Photo: $1=$ picture, $2=$ photo, $3=$ chart, $4=$ infographic $5=$ other

14-Actor: $1=$ individual figure Muslim; $2=$ group figures Muslim 3= political figure Non-Muslim; $4=$ group figures Non- Muslim, $5=$ celebrity $6=$ Terrorist $7=$ other

15- Active state : $1=$ threatening; $2=$ angry/ 'crazy'; $3=$ animated; $4=$ crying; 5= sad; $6=$ neutral; $7=$ calm $/$ placid $; 8=$ focused $/$ concentrating; $9=$ friendly; $10=$ happy/smiling; $11=$ laughing; $12=$ speaking; $13=$ other. 